\title{
Assessing the importance of managerial accuracy of perceptions
}

\author{
Yeamduan Narangajavana • \\ Fernando J. Garrigos-Simon • Ignacio Gil-Pechuan
}

Published online: 13 February 2013

(C) International Network of Business and Management 2013

\begin{abstract}
This article sets out to observe how the accuracy of perception by hospitality managers of the new competitive framework arising out of the advent of the internet has affected the choice of strategy and entrepreneurial performance. In order to achieve this aim, we use a combination of two different empirical studies: firstly, a Delphi study addressed to experts from around the world and secondly, a questionnaire addressed to managers in the Spanish hospitality sector. The study uses Structural Equation Modeling methodology and highlights the importance of managerial perception. Our results confirm the importance of the schemes established.
\end{abstract}

Keywords Accuracy of perception $\cdot$ Competitive strategies $\cdot$ Performance $\cdot$ SEM

\section{Introduction}

The literature on human resource management (HRM) has produced in-depth studies on the relationship between several HRM practices and the way they influence performance (Guest 1997; Akhtar et al. 2008; Ngo et al. 2008; Subramony 2009). Recent trends in research have stressed the essential role of knowledge processes on firm performance. However, and although previous studies have suggested that HRM practices and knowledge-related outcomes are associated (Minbaeva 2005; Yamao et al. 2009), researchers "have recognized that the

\footnotetext{
Y. Narangajavana

School of Management, Walailak University, 222 Thaiburi, Thasala District, Nakhon Si Thammarat 80160, Thailand

F. J. Garrigos-Simon · I. Gil-Pechuan ( $₫)$

Department of Business Organization, Universitat Politècnica de València, 7D Building, 1st floor, Camino de Vera, S/N, 46022 Valencia, Spain

e-mail: igil@doe.upv.es
} 
traditional prescriptions of high-performance HRM practices are not relevant for knowledge processes" (Minbaeva et al. 2009, p. 478).

An explanation for this lies in the fact that "the contribution of HRM practices to product innovation and performance is conditioned by the employees' knowledge" (Lopez-Cabrales et al. 2009, p. 486), and more specifically by managers' knowledge. Nevertheless, “only a few studies have analyzed how employees' knowledge and HRM practices, on the whole, can enhance organizations' innovative activity" (Lopez-Cabrales et al. 2009, p. 496).

Recent HRM literature has drawn attention essentially to the role of HRM practices in developing incentives for top managers (Berrone and Gomez-Mejia 2009) in creating knowledge stocks and promoting knowledge transfer (Yamao et al. 2009; Kae et al. 2009) or specifically in improving employee skills or knowledge (Lepak and Snell 1999; Lopez-Cabrales et al. 2009). Nevertheless, few studies examine the connection between managers' knowledge, measured by the accuracy of their perceptions, and its influences on firm strategy and performance.

The importance of managerial accuracy of perception, and its implications for HRM, is key, as was postulated early on by Yammarino and Atwater (1993) in an article published in a special issue of Human Resource Management focused on understanding the relationship between the self and other ratings (see also Nilsen and Campbell 1993; Tornow 1993; Van Velsor et al. 1993), in which these authors posited that accurate self-perceptions may be associated with enhanced individual and organizational outcomes.

Nevertheless, and surprisingly, since then, although there has been extensive research in psychologic literature about the importance of self-assessment, self-awareness, or performance evaluation in work setting, little research has focused on the incidence of managers' accuracy of perception in decision making and in managerial outcomes (Starbuck and Mezias 1996; Mezias and Starbuck 2003). This fact could be explained, as Winter (2003, p. 43) suggests, because assessing how the quality of decision making is influenced by mistaken perceptions might be very challenging.

In order to fill this gap, and prior to possibly studying the influence of HRM practices in improving managers' accuracy of perceptions, as a measure of managerial knowledge, we will study how managers' accuracy of perceptions conditions company strategies and performance. Specifically, this study will try to analyze the significance of the accuracy of managerial perception of the new environment that has emerged with the development of the internet in the Spanish hospitality industry, its relevance in the choice of the most appropriate strategies, and how it affects performance. Our empirical investigation uses a Delphi study with a panel of international experts and a sample of 189 hospitality enterprises, and attempts to corroborate the hypotheses established by the use of Structural Equation Modeling methodology.

\section{The importance of managers' accuracy of perceptions}

The rise of environmental turbulence has forced firms to keep abreast with alterations by making rapid responses or actively anticipating changes. This fact is 
especially important to the hospitality industry where the transformations of businesses necessarily oblige firms to perceive or identify opportunities in order to survive and grow.

Managerial literature has broadly highlighted the importance of looking for, developing, and managing the information and knowledge inside firms in order to face the new environment. This point is stressed by the resources and capabilities view (Wernerfelt 1984; Prahalad and Hamel 1990), specifically the knowledgebased (Grant 1996) and the dynamic capabilities (Teece 2007) perspectives or the theories that focus on learning organizations (Pedler et al. 1991), knowledge management, or intellectual capital. The right knowledge at the right time in the correct format and in an accessible form is clearly an invaluable asset for an organization (Hult 2003, p. 194). Moreover, Wang et al. (2009, p. 1265) state that "resource and knowledge-based research generally maintains that among the types of firm-specific resources examined, firm-specific knowledge has the greatest potential to serve as a source of sustainable competitive advantage."

However, it is people who manage knowledge. In this vein, firms require managers to deal with complexity and learn how to know precisely the way a future event will be revealed or even if it will happen. As Teece (2007, p. 1346) points out, "dynamic capabilities reside in large measure with the enterprise's top management team" in general or specifically with the CEO in the case of small- and mediumsized enterprises. This is explained by the fact that managers "can sense and even help shape the future, unshackle the enterprise from the past, and stay ahead by augmenting knowledge assets, protecting them with intellectual property rights, establishing new value enhancing asset combinations, and transforming organizational and, if necessary, regulatory and institutional structures." The argument is also stressed by Mohrman and Worley (2009, p. 434), who point out that a dynamic capability-building approach will only happen "if corporate leaders have a clear idea of the behaviors they want to instill in the organization and the organizational approaches that can foster them."

Obviously, the "clear idea" requires accuracy on the part of managers in their perceptions of the crucial factors affecting the success of their enterprises in order to be able to implement adequate policies to deal with them. "Managers' perceptions form the basis for the firm's actions and strategies" (Starbuck and Mezias 1996, p. 100). In this sense, "it is well established in the literature that strategic decisions... are based on management perceptions" (Arend 2006, p. 756). However, "it is well-established in behavioral decision research that management perception is subject to a variety of biases and distortions" (Powell et al. 2006, p. 176), a fact that explains the accuracy of perceptions as the key factor influencing the choice of appropriate firm strategies and through it, the performance of firms.

Perception can be defined as an active mental process, comprising the selection, organization, structuralization, and interpretation of information in order to infer from and make sense of the information (Rollinson et al. 1998). Our term "includes everything that goes into managers' understanding of their work situation" (Mezias and Starbuck 2003, p. 4). Perceptual phenomena incorporate several components and although there are alternatives such as awareness, belief, cognition, estimation, and sensemaking, following the ideas of Mezias and Starbuck (2003, p. 4), we 
consider that "the term 'perception' best denotes the entire complex of related phenomena."

Correct managerial perception is crucial to coping with the environment as these perceptions can be translated to the performance of their firms. In particular, the accuracy of managerial perception is critical for small- and medium-sized enterprises, where the perceptions of the top managers directly guide the strategic behavior of firms.

Firstly, our viewpoint is based on the fact that strategic decisions reflect the rational limits of decision makers (March and Simon 1958). The world, as it is perceived, is a world where behavior is important (Robbins 1998, p. 90). Hence, managers, as individuals, do not react to stimuli, but to what we interpret the stimuli to be (Wyer et al. 2000). Obviously, managers of different firms in the same sector can develop different interpretations or perceptions about their environment (Child 1972; Daft and Weick 1984), which influences their different reactions.

Secondly, individual perceptions are essential because they influence the strategic behavior of organizations (Arend 2006). We are conscious that there is a certain controversy in the literature surrounding the role that top managers can play in the performance of their enterprise. However, in recent years, management researchers have increasingly emphasized the influence of the manager in corporative performance. Our claims are justified by and grounded in particular in the entrepreneurial school, in streams such as strategic choice and adaptation literature (Child 1972; Pfeffer and Salancik 1978), diverse theories that stress the influence of leadership and top managers on organizations (Hambrick and Mason 1984; Ensley et al. 2000), or even the theories that emphasize the determinism of the environment (i.e., Winter 2003, p. 43, relates how strategy decision making is peculiarly vulnerable to different misperceptions related to the logic of competitive processes). This fact is also implicitly supported by the HRM literature where "competency-based leadership development has received increasing attention for its potential to create firm-specific expertise and to foster high-performing organizations" (Brownell 2006, p. 309). According to all these positions, in the end, the manager of the enterprise is responsible for its strategic formulation, either directly or indirectly through the conformation of an organization that assures the successful alignment between the firm and its environment.

Finally, and despite the greater or lesser extent of managerial influence, what is clear is that the decision-making process influences firm performance. Most empirical studies into managerial decisions suggest that the strategic decisions taken by managers have a substantial impact on the firm's long-term performance (Song et al. 2002, p. 970). Specifically the effects of management perception on performance attributions and decision processes have been established in a variety of contexts and across a wide range of decision biases and heuristics (Powell et al. 2006 , p. 185). Hence, as much as the opinion of managers will be close to the objective reality, strategic decisions will be more congruent and the firm success will be higher (Hambrick and Mason 1984; Song et al. 2002).

In short, the literature in general outlines the relationship between the perception of top managers, their behavior, and strategic change, and between managerial behavior (or strategies) and firm performance. 
However, it is impossible to measure all the perceptions of managers. We have focused on the perceptions of the Spanish hospitality managers in the post-internet structural environment because "businesses in the hotel industry have faced massive changes due to the information technology revolution" (Yang and Wan 2004, p. 594) and because the internet and the advances of information technologies have changed the way of doing business and even the comprehension of the competitive environment (Wahab and Cooper 2001). Hence, we can formulate the following hypotheses:

H1 The accuracy of managerial perception of the post-internet structural environment has a positive effect on firm performance.

H2 The accuracy of managerial perception of the post-internet structural environment has a positive effect on firm performance. This effect is mediated by the ability of managers to articulate the most convenient competitive strategy, according to their own perception.

These hypotheses are expressed in Fig. 1, where $\xi_{1}$ indicates the latent variable as a summary of the inaccuracy of perception of the post-internet competitive environment, $\eta_{2 \mathrm{i}}$ represents the mediating role of the various competitive strategies, and $\eta_{1 \mathrm{i}}$ expresses the mediation of the different variables of firm performance.

In addition, and given the role that we have assigned to competitive strategies, as mediating the accuracy of managerial perception and performance, let us consider an epigraph to the explanation of the model of competitive strategies used in this study.

\section{Competitive strategies: the Miles and Snow typology}

The literature has focused a great deal of attention on the quest for the strategic construct, with several classification schemes, which attempt to measure or capture the essence or content of most competitive postures, investment strategies, or patterns of strategic behavior (Robinson and Pearce 1988).

Defined as "sets of firms that are similar in terms of important characteristics" (Short et al. 2008, p. 1053), the study of strategic groups or configurations "has occupied an important and central role in both organization theory and strategy research" (Fiss 2007, p. 1180). Today, from the diverse conceptions formulated in recent years, a broad section of the literature stresses the relevance of the typology developed by Miles and Snow (1978).

The strategic typology of Miles and Snow (1978) has been the subject of extensive theoretic and empirical examination (Hambrick 1983; Zahra and Pearce 1990), and can be considered as the typology that has received the greatest amount of research attention in management and marketing literature (DeSarbo et al. 2005; Kabanoff and Brown 2008). Numerous studies have examined the link between Miles and Snow's strategy types and performance (Hambrick 1983; Zajac and Shortell 1989), as well as the moderating effects of these strategy types on the influence of environment, or organizational structure, behavior, processes, and capabilities (Davies and Walters 2004; Olson et al. 2005; Slater et al. 2006). The 


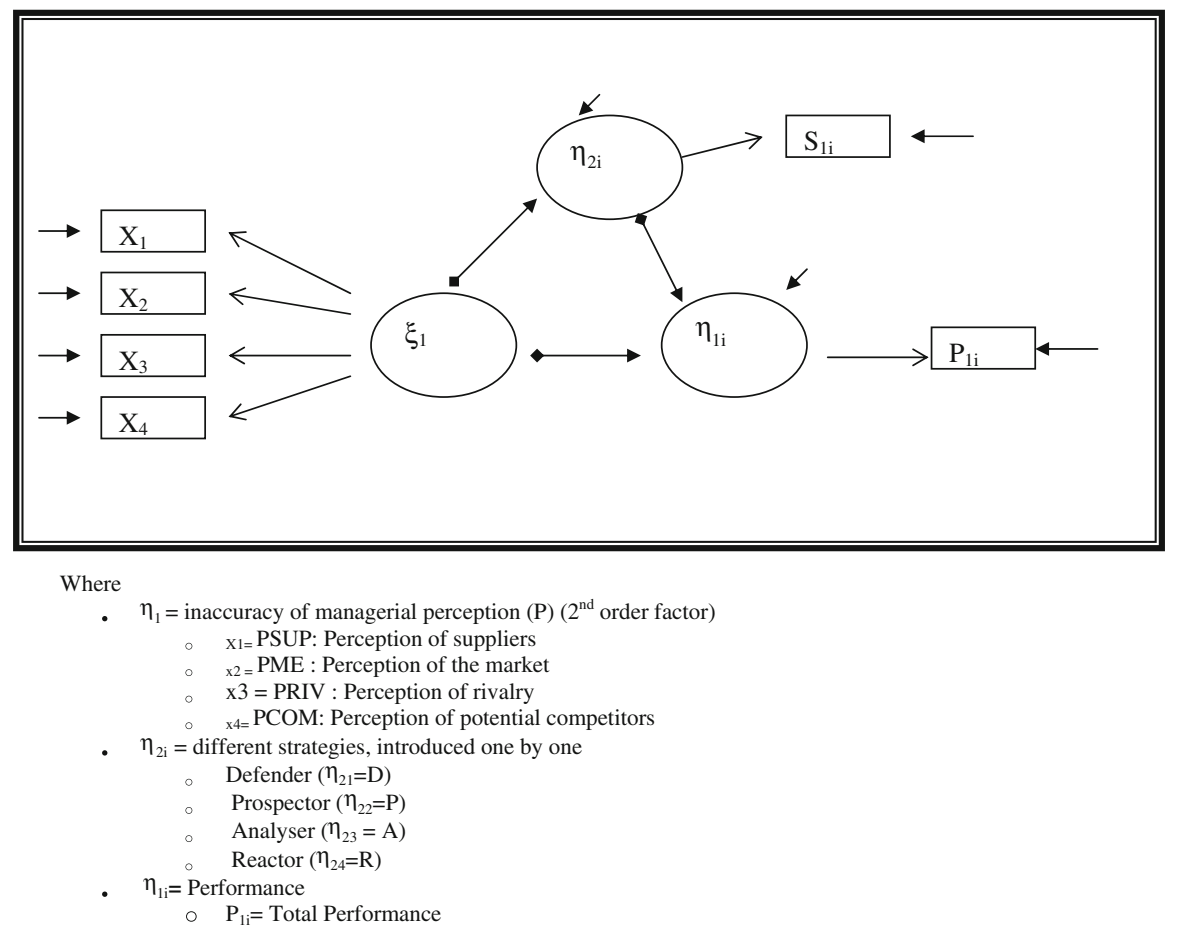

Fig. 1 Path diagram of the perception-strategies-performance causality model. $\xi_{1}$ Inaccuracy of managerial perception (P) (2 ${ }^{\text {nd }}$-order factor): $X_{1} P S U P$ perception of suppliers; $X_{2} P M E$ perception of the market; $X_{3}$ PRIV perception of rivalry; $X_{4}$ PCOM perception of potential competitors. $\eta_{2 i}$ Different strategies, introduced one by one: Defender $\left(\eta_{21}=D\right)$; Prospector $\left(\eta_{22}=P\right)$; Analyzer $\left(\eta_{23}=A\right)$; Reactor $\left(\eta_{24}=\mathrm{R}\right) . \eta_{1 i}$ Performance: $P_{1 i}$ total performance. Note: Data significance of each variable are in the table

various empirical studies that apply Miles and Snow's model have strongly supported this model in different environments (Zahra and Pearce 1990). Moreover, considerable psychometric assessments have supported the validity and reliability of this approach and have identified it as being internally consistent and as being especially sound in terms of codification and prediction (Hambrick 1983; Conant et al. 1990; Shortell and Zajac 1990).

The Miles and Snow's typology focuses on the process of dynamic interaction and adjusting to environmental change in the firm, which "takes into consideration the trade-off between external and internal strategic factors" (O'Regan and Ghobadian 2005, p. 83-84). It reflects a complex vision of organization processes and the environment as well as the attributes of products, market, technology, organizational structure, and managerial characteristics (Smith et al. 1989), thus being able to provide the most thorough description of organizational characteristics associated with each strategy (Dent 1990).

We have also chosen this classification as the literature stresses its suitability in the particular cases of SMEs (O'Regan and Ghobadian 2005). Moreover, it has been suggested that the configurational approach can be extended to apply to areas such as HRM, organizational behavior, ethics, entrepreneurship, and international 
business (Short et al. 2008, p. 1053). For example, Miles and Snow's typology is used by Kabanoff and Brown (2008) in a study focusing on how individual top teams develop their strategic knowledge structures via interaction with their environment, a fact that justifies our approach.

Miles and Snow (1978) proposed that competing firms within an industry show patterns of behavior representing four basic strategic types: Prospectors, Defenders, Analyzers, and Reactors. DeSarbo et al. (2005, p. 47-48) describe these types perfectly, "Prospectors are technologically innovative and seek out new markets; Analyzers tend to prefer a 'second-but-better' strategy; Defenders are engineeringoriented and focus on maintaining a secure niche in relatively stable market segments; and Reactors lack a stable strategy and are highly responsive to short-term environmental exigencies." According to Miles and Snow (1978), organizations in each category show a consistent or relatively stable pattern of strategic behavior in their decisions when dealing with various environmental forces (Conant et al. 1990).

The Miles and Snow (1978) typology takes as a theoretic model the strategic choice focus. The premise is that the manager is capable of choosing from among various stable organizational forms. This therefore implies that if the firm chooses a certain strategy and the design of an organization is coherent with this strategy, this organization will be an effective competitor for a long time to come in the industry (Miles and Snow 1978, p. 14). In this vein, many studies suggest that the strategic types known as Prospectors, Analyzers, or Defenders have the opportunity to be equally successful in their activities (Miles and Snow 1978; Conant et al. 1990; Wright et al. 2001). This hypothesis is in line with the concept of equifinality, which suggests that the same performance can be reached through different means, with diverse resources, processes, and methods (Hrebiniak and Joyce 1985). The hypothesis of equifinality could be established in the following way:

H3 The strategies of Prospector, Defender, and Analyzer can be equally effective and lead to good performance in an industry, as long as the strategy is proficiently established. Hence, there should not be any statistically significant differences in the results of the three strategic types.

According to DeSarbo et al. (2005, p. 49), more than one strategic type can be successful in a given environment if firms are organized appropriately, are consistent in their strategic selection, and the planning and implementation of strategies is effective. The profiles Prospector, Analyzer, and Defender are defined by the literature as positive profiles, in the sense that they manage to adapt to the environment. However, and in contrast, the Reactor type is perceived as negative because its lacks any intentional strategy and usually responds inappropriately to environmental pressures as they arise, which can lead to an unstable or inconsistent adaptation pattern since it lacks internal coherence in its strategic and organizational design. "Reactors do not capitalize on the set of capabilities they have already built up, but rather they shift strategic orientation in reaction to competitive pressures, thus they will usually be at a disadvantage to those firms that are competing from an established position of strength" (DeSarbo et al. 2005, p. 50). Hence, it will become an ineffective competitor within the industry (Miles and Snow 1978, p. 93). In this 
vein, the first three types will always outperform reactors (Miles and Snow 1978; Conant et al. 1990; Wright et al. 2001), and we can hypothesize the following:

H4 The three positive archetypal profiles (Prospector, Defender, and Analyzer) will produce better results than the reactor profile within an industry.

Finally, and taking into account all the previous hypotheses, we can propose the following:

H5 Managers with better accuracy of perception will implement in their firms one of the three positive archetypal profiles, as these will obtain better results than the reactor profile.

\section{Methodology}

Our study makes use of two main data sources, from the comparison of which we measure the accuracy of managerial perception: a Delphi study performed with international experts to measure the subjects' perception of the post-internet competitive environment and a questionnaire addressed to hotel enterprise chief executives to collect their individual opinions on the same questions. The latter also provides information about the strategies employed by the different enterprises and their performance. A two-phase structural equation methodology is used to validate variables and relationships (Fig. 1).

The Delphi study gathers expert opinions on the post-internet hospitality structural environment, using the Porter (2001) 17-item scale in each one of a sevenpoint Likert style. The Delphi study was undertaken with Spanish and international experts from 10 countries from Asia, America, and Europe, obtaining an acceptable number of 19 replies with an acceptable degree of consensus in the final round. These data are considered to be of good quality or accurate as they came from qualified experts and were collected with an appropriate convergence method.

The questionnaire to the CEOs of hospitality enterprises shows their individual opinions on the same questions put to the experts in the Delphi method. The final sample was of 189 questionnaires with a sample error of $5.48 \%$ and was without a non-response bias. The entire sample is made up of small- and medium-sized enterprises (fewer than 250 employees), with $44.4 \%$ of organizations classified as micro-firms (fewer than 10 employees). The inaccuracy of managerial perception of each manager for each item of Porter's scale is measured as the square difference between the individual opinion of each top manager for each variable and the arithmetic mean of each variable obtained in the Delphi study.

In addition, from the questionnaire to managers, we measured Miles and Snow's strategic typology following Snow and Hrebiniak's (1980) paragraph approach, which has been commonly used and extensively validated (Davig 1986; Rajagopalan 1996). Moreover, the measurement of performance was based on a scale of 10 items, in a seven-point Likert style, which includes items used by authors such as Tracey et al. (1999) and Nahm et al. (2004). The scale combines aspects of performance related to capital profitability (3 indicators: ROA, ROI, ROS), growth (3 indicators: growth in 
sales, market share increase, and market value/accounting value), stakeholder satisfaction ( 2 indicators, referring to customers and employees), and the strength of the competitive position of the firm ( 2 indicators: the competitive strength and the success rate in launching new products). The database was created using SPSS.

This study uses a two-phase structural equation methodology (Anderson and Gerbing 1988; Shook et al. 2004). Robust Standard Estimators, Satorra-Bentler Chi-square, and the statistical program EQS 5.7b are used. The two-phase approach begins with the analysis of the measurement model. Unidimensionality, reliability, and validity of the different constructs are assessed with confirmatory factor analysis. Constructs with unacceptable fits are respecified by deleting the indicators that failed to preserve the unidimensionality of the measurement, that are of little significance, or that have a coefficient alpha of below 0.3 (Anderson and Gerbing 1988). The causal relationships between the different constructs are then analyzed using covariance structure models.

Individual and composite reliabilities are estimated. The composite reliability scores of all constructs are above 0.7 in all cases (Hair et al. 1998). Two types of validity measures (discriminant validity and convergent validity) are examined.

The path diagram of our model is shown in Fig. 1. The model considers the inaccuracy of perception of the post-internet competitive environment $\left(\mathrm{P}=\xi_{1}\right)$ as an exogenous variable. This variable is conceived by the data as a second-order factor with four dimensions. Hence, and in order to resolve the complexity of our model and to simplify the estimation process (Landis et al. 2000), this latent variable is explained by four items or composite variables (with the sum of the indicators).

In order to measure the endogenous variables, we first use as first-order endogenous variables or mediating variables the competitive strategies according to the Miles and Snow typology. These are dichotomous variables, which have a value of 1 when each strategy is used or 0 when the strategy established is not used. They are called (1) Defender $\left(\eta_{21}=\mathrm{D}\right)$; (2) Prospector $\left(\eta_{22}=\mathrm{P}\right)$; (3) Analyzer $\left(\eta_{23}=A\right)$; and (4) Reactor $\left(\eta_{24}=\mathrm{R}\right)$. These strategies are explained by the accuracy of managerial perception of the post-internet competitive environment.

Secondly, we observe firm performance as a latent endogenous variable. In this case, with the aim of guaranteeing the convergence of the results, we previously performed an exploratory factorial analysis (the dimensionality of the four factors established above was used for a later confirmatory analysis). We then observed performance $\left(\eta_{11}=P\right)$ as an overall aggregate variable from the previous 4 dimensions, also tested and compiled with a confirmatory factor analysis. Performance is explained both directly by perceptual inaccuracy to test $\mathrm{H} 1$ and indirectly. The relationship between perceptual inaccuracy and competitive strategy is examined to test $\mathrm{H} 2$.

The global fit measurement of each model is assessed in Table 1. Most of the indices reach the desired values, reflecting an acceptable fit for all the models. Firstly, the fit of the models, especially the goodness of incremental fit measures such as AGFI or BBNFI, corroborates convergent validity. Secondly, the magnitude of factorial weightings, with values greater than or near 0.4 (Hair et al. 1998), also insures this validity. Thirdly, the statistical significance of each weight obtained between the indicator and the latent variables ( $t$ value greater than 1.96 with $\alpha=0.05$ ) also confirms this validity. Discriminant validity is also corroborated. 
Table 1 Fit measures of the different models

\begin{tabular}{|c|c|c|c|c|c|c|}
\hline & \multirow[t]{2}{*}{$\begin{array}{l}\text { Inaccuracy of } \\
\text { perception }\end{array}$} & \multirow[t]{2}{*}{ Total perf. } & \multicolumn{4}{|c|}{$\begin{array}{l}\text { Different causal models of inaccuracy of } \\
\text { perception-configurative competitive } \\
\text { strategies-performance }\end{array}$} \\
\hline & & & $\begin{array}{l}\text { Defender } \\
\text { IP-Def-P }\end{array}$ & $\begin{array}{l}\text { Prospector } \\
\text { IP-Pros-P }\end{array}$ & $\begin{array}{l}\text { Analyzer } \\
\text { IP-Ana-P }\end{array}$ & $\begin{array}{l}\text { Reactor } \\
\text { IP-Reac-P }\end{array}$ \\
\hline \multicolumn{7}{|l|}{ Identification } \\
\hline Degrees of freedom & 26 & 2 & 8 & 8 & 8 & 8 \\
\hline \multicolumn{7}{|l|}{ Estimation } \\
\hline \multicolumn{7}{|l|}{ Absolute fit measures } \\
\hline Satorra-Bentler $\chi^{2}$ & 30.055 & 3.02 & 13.441 & 8.338 & 13.996 & 15.447 \\
\hline Sig. level & 0.265 & 0.220 & 0.098 & 0.401 & 0.082 & 0.051 \\
\hline GFI & 0.950 & 0.991 & 0.965 & 0.978 & 0.965 & 0.961 \\
\hline RMSEA & 0.075 & 0.065 & 0.092 & 0.057 & 0.091 & 0.104 \\
\hline \multicolumn{7}{|c|}{ Incremental fit measures } \\
\hline AGFI & 0.895 & 0.953 & 0.909 & 0.943 & 0.908 & 0.898 \\
\hline BBNFI & 0.927 & 0.975 & 0.942 & 0.963 & 0.945 & 0.939 \\
\hline BBNNFI & 0.931 & 0.966 & 0.931 & 0.973 & 0.934 & 0.920 \\
\hline RCFI & 0.984 & 0.988 & 0.966 & 0.998 & 0.963 & 0.941 \\
\hline IFI & 0.961 & 0.989 & 0.964 & 0.986 & 0.966 & 0.958 \\
\hline \multicolumn{7}{|c|}{ Parsimony fit measure } \\
\hline $\mathrm{NC}$ & 1.156 & 1.51 & 1.643 & 1.042 & 1.749 & 1.931 \\
\hline
\end{tabular}

Where recommended values are Significance of Satorra-Bentler $\chi^{2} \geq 0.05$, GFI (goodness of fit index) $\geq 0.90, R M S E A$ (Root mean square error of approximation) $\leq 0.08, A G F I$ (adjusted goodness of fit index) $\geq 0.90, B B N F I$ (Bentler-Bonnett normed fit index) $\geq 0.90$, BBNNFI (Bentler-Bonnett not-normed fit index) $\geq 0.90, R C F I$ (robust comparative fit index) $\geq 0.90$, IFI (incremental fit index) $\geq 0.90, N C$ (normed $\chi^{\overline{2}}$ ). Normally between 1 and 2, although values of up to 5 are considered acceptable

\section{Empirical contrast of hypotheses}

Once the fit of all the measurement models was corroborated, the fit of the structural estimated models was used to determine the significance level of the estimated parameters and the reliability of the structural equations. In Table 2, we can observe the direct and indirect effect that the accuracy of managerial perception has on each performance measurement when we use the different strategies.

The data strengthen our theoretic arguments and lend support to the corroboration of Hypothesis H2: the existence of a large, statistically significant indirect effect confirms the importance of competitive strategies as mediating in the explanation of performance.

A close observation of each model reveals the importance of the accuracy of managerial perception. One strategy, the reactor strategy, is also revealed to negatively affect performance (Hypothesis H4) as it shows a lack of any kind of strategy. In general, the model recommends following the analyzer strategy, 
Table 2 Estimated parameters of the causal structural models that relate perception, competitive strategies, and the different measures of performance

\begin{tabular}{lcccc}
\hline Strategy & \multicolumn{3}{c}{$\begin{array}{l}\text { Different models of inaccuracy of perception- } \\
\text { strategies-performance }\end{array}$} \\
\cline { 2 - 5 } & Defender & Prospector & Analyzer & Reactor \\
\hline Indirect effect (perception-performance) & -0.001 & 0.004 & -0.003 & -0.088 \\
Signif. $(t)$ & $(-0.229)$ & $(0.544)$ & $(-0.159)$ & $(-2.498)$ \\
Perception-strategy: coef. $\gamma_{1 \mathrm{i}}$ in $\eta_{2 \mathrm{i}}=\gamma_{1 \mathrm{i}} \xi_{1}+\zeta_{1 \mathrm{i}}$ & -0.019 & 0.051 & -0.248 & 0.388 \\
Signif. $\left(t_{\text {rob }}\right)$ & $(-0.284)$ & $(0.616)$ & $(-3.587)$ & $(3.318)$ \\
Strategy-performance: coef, $\beta_{2 \mathrm{i}}$ in & 0.046 & 0.073 & 0.012 & -0.225 \\
$\eta_{1 \mathrm{i}}=\beta_{3 \mathrm{i}} \xi_{1}+\beta_{2 \mathrm{i}} \eta_{2 \mathrm{i}}+\zeta_{2 \mathrm{i}}$ & & & & \\
Signif. $\left(t_{\text {rob }}\right)$ & $(0.581)$ & $(0.935)$ & $(0.154)$ & $(-2.741)$ \\
Direct effect (perception-performance) & -0.071 & -0.075 & -0.067 & 0.018 \\
Perception-performance: coef. $\beta_{3 \mathrm{i}}$ in & -0.071 & -0.075 & -0.067 & 0.018 \\
$\eta_{1 \mathrm{i}}=\beta_{3 \mathrm{i}} \xi_{1}+\beta_{2 \mathrm{i}} \eta_{2 \mathrm{i}}+\zeta_{2 \mathrm{i}}$ & & & & \\
Signif. $\left(t_{\text {rob }}\right)$ & $(-0.995)$ & $(-1.076)$ & $(-0.906)$ & $(0.252)$ \\
Total effect & -0.071 & -0.071 & -0.070 & -0.069 \\
Reliability of structural equations $\left(R^{2}\right)$ & 0.007 & 0.010 & 0.005 & 0.048 \\
\hline
\end{tabular}

although there is no significant difference from the other positive strategies (Hypothesis H3). In this vein, H5 is also confirmed, as the managers with better accuracy of perception will implement one of the three positive archetypal profiles in their firms, as they will have better results than the reactor profile.

These results emerge from the following reflections.

Firstly, the criterion of quality of managerial perception points to the analyzer strategy $\left(\eta_{23}=A\right)$ as the best choice of strategy, while revealing the reactor strategy $\left(\eta_{24}=R\right)$ as the one to be avoided. This can be deduced firstly because these are the only significant relations to emerge between perception-strategy in all the different models ( $t$ robust of -3.587 for the analyzer and of 3.318 for the reactor). In addition, here we can also observe the most important coefficients $\gamma_{1 i}$ of -0.248 for the analyzer strategy model and +0.388 for the reactor strategy models. The positive or negative sign of these relationships must also be considered. The sign is explained by the use of "inaccuracy" of managerial perception, so a negative correlation indicates that good perception recommends choosing this strategy, while a positive correlation indicates that only a bad perception could recommend this strategy. In addition, the only significance of the analyzer strategy from among all the positive strategies could be explained due to introducing each strategy individually into the model and the fact that the respondents of the other positive strategies represent half of the number respondents to the analyzer strategy.

If we observe the relationships between strategies and firm performance, all our hypotheses are again confirmed. In this way, a positive correlation is seen to emerge between the choice of the analyzer strategy and obtaining good firm performance since the coefficient $\beta_{2 \mathrm{i}}$ for this strategy is positive, though not significant. Indeed, all the good types show positive relationships, although none of them is completely 
significant (we have to take into account that we have observed each dimension individually in the empirical contrast, which means that there are no significant differences between the positive profiles), a fact that supports the equifinalist hypothesis (H3), which suggests that each of the positive profiles can be satisfactory. However, we can see that the choice of the reactor strategy negatively affects the results (Hypothesis 4 ) since the coefficient $\beta_{2 \mathrm{i}}$ in this situation has a value of -0.225 , with a significance level of -2.741 . This result supports the relation previously obtained, which indicates that accurate managerial perception would never choose this strategy because of its negative effect on firm performance (Hypothesis 5).

We can also draw various conclusions from the above. Firstly, each of the typologies, with the exception of the reactor strategy which effectively has no strategy, may be valid, as in every case they indicate positive results (Hypothesis 4). This falls perfectly in line with the Miles and Snow model, which states that every strategy can produce good results except for the lack of strategy (reactor), but none is better than the other (Hypothesis 3). This can be observed by the positive correlations between the defender, prospector and analyzer strategies and performance. However, these relationships are not significant. This may be due to the theory itself or the methodological problem of using categorical variables and comparing some dichotomous variables. This lack can be also observed in the low reliability of the structural equations. However, in this question, we can also observe how the relative reliability of the reactor strategy is greater by far than the others, which also lends support to our conclusions. In this way, we can see how all the indirect relationships are explained with a positive sign in this strategy and, furthermore, how all of them are highly significant. In addition, the criterion of the accuracy of managerial perception of the post-internet competitive environment recommends following the analyzer strategy. However, the relationship between this strategy and firm performance is not significant, although it is positive, as the model predicts.

Finally, we must also observe the importance of the mediation of competitive strategies between managerial perception and performance (Hypothesis 2) as, in every model, the direct effects are not significant and the coefficients are very low (Hypothesis 1). This fact confirms and corroborates Hypothesis 2 ahead of Hypothesis 1.

\section{Conclusion}

This study has examined and empirically revealed the decisive importance of the accuracy of managerial perception of the post-internet competitive environment in firm performance. This is essential for HRM due to the fact that their practices should emphasize the importance of being designed and implemented with the aim of improving these perceptions.

Specifically, our results $(\mathrm{H} 2)$ strengthen the theoretic proposal that emphasizes the importance of the accuracy of managerial perception in firm performance, through the mediation of competitive strategies, measured with the Miles and Snow (1978) typology. Our criterion of the accuracy of managerial perception also posits and empirically supports the equifinalist approach, suggesting that each positive strategic archetype is an effective form of competing and organizing, while they do reject following the so-called 
reactor strategy (Hypothesis H3 and H4), as managers with inaccurate perceptions choose this strategy, and the development of this strategy negatively affects performance (Hypothesis H5). Finally, the direct effect of the accuracy of managerial perception on performance, without the mediation of any strategy, is not significant, showing few coefficients, thus lending weight to the testing of hypothesis $\mathrm{H} 1$.

Although our study provides empirical evidence in favor of the equifinalist hypothesis (Miles and Snow 1978; Snow and Hrebiniak 1980; Smith et al. 1989; Conant et al. 1990), some authors (Zajac and Shortell 1989; DeSarbo et al. 2005) have indicated that different environments could favor different strategic types and in general the analyzer type outperforms the prospector and defender types on profitability measures (Hambrick 1983; Kabanoff and Brown 2008). In this vein, the criterion of our accuracy of managerial perception shows that the managers who had better perceptions significantly chose the analyzer strategy, which effectively is the one with higher average profitability if we do an ANOVA test, although not in a significant way. This is due to the way in which we measured performance, which includes more items than just profitability measures, although this is a task for further studies.

The practical applications of our study should be considered for the implementation of HRM policies. First of all, the analysis clearly highlights that the accuracy of perception of the post-internet competitive environment enables managers to choose the most recommendable strategy due to its relationship with performance. In this vein, HRM practices should be designed to contribute to the improvement of managerial perceptions. Secondly, our study indicated that managers with better perceptions chose the strategies that affected the capital profitability of their enterprises more positively, although it would not be the best strategy to get the best general performance from their enterprises. The reason could be that possibly managers' personal rewards, directly or indirectly, are influenced more by the capital profitability (short term) of the firm than by its general performance (long term). This research stresses the need to review HRM reward systems, although this might be the object of future more in-depth research. Finally, Winter (2003, p. 39) shows other important aspects of the accuracy of perceptions.

Inferences drawn from this study should take into account the limitations of our sample and the methodology used. Further research might take the same perspective with different samples in the sectors such as tourism or might consider using different methodologies.

\section{References}

Akhtar, S., Ding, D. Z., \& Ge, G. L. (2008). Strategic HRM practices and their impact on company performance in Chinese enterprises. Human Resource Management, 47(1), 15-32.

Anderson, J. C., \& Gerbing, D. W. (1988). Structural equation modeling in practice: A review and recommend two step approach. Psychological Bulletin, 103(3), 453-460.

Arend, R. J. (2006). SME-supplier alliance activity in manufacturing: Contingent benefits and perceptions. Strategic Management Journal, 27(8), 741-763.

Berrone, P., \& Gomez-Mejia, L. (2009). The pros and cons of rewarding social responsibility at the top. Human Resource Management, 48(6), 959-971.

Brownell, J. (2006). Meeting the competency needs of global leaders: A partnership approach. Human Resource Management, 45(3), 309-333. 
Child, J. (1972). Organizational structure, environment and performance: The role of strategic choice. Sociology, 6(1), 1-22.

Conant, J. S., Mokwa, M. P., \& Varadarajan, P. R. (1990). Strategic types, distinctive marketing competences and organizational performance: A multiple measures-based study. Strategic Management Journal, 11(5), 365-383.

Daft, R. L., \& Weick, K. E. (1984). Toward a model of organizations as interpretation systems. Academy of Management Review, 9, 284-295.

Davies, H., \& Walters, P. (2004). Emergent patterns of strategy, environment and performance in a transition economy. Strategic Management Journal, 25, 347-364.

Davig, W. (1986). Business strategies in smaller manufacturing firms. Journal of Small Business Management, 24(1), 38-46.

Dent, J. F. (1990). Strategy, organisation and control: Some possibilities for accounting research. Accounting Organisations and Society, 15(1/2), 3-25.

DeSarbo, W. S., Di Benedetto, C. A., Song, M., \& Sinha, I. (2005). Revisiting the Miles and Snow strategic framework: Uncovering interrelatinships between strategic types, capabilities, environmental uncertainty, and firm performance. Strategic Management Journal, 26, 47-74.

Ensley, M. D., Carland, J. W., \& Carland, J. C. (2000). Investigating the existence of the lead entrepreneur. Journal of Small Business Management, 38(4), 59-77.

Fiss, P. C. (2007). A set-theoretic approach to organizational configurations. Academy of Management Review, 32(4), 1180-1198.

Grant, R. M. (1996). Toward a knowledge-based theory of the firm. Strategic Management Journal, 17(10), 109-122.

Guest, D. (1997). Human resource management and performance: A review and research agenda. The International Journal of Human Resource Management, 8, 263-276.

Hair, J. F., Anderson, R. E., Tatham, R. L., \& Black, W. C. (1998). Multivariante date analysis. Englewood Cliffs, NJ: Prentice Hall.

Hambrick, D. C. (1983). Some test of the effectiveness of functional attributes of Miles and Snow's strategic types. Academy of Management Journal, 26(1), 5-26.

Hambrick, D. C., \& Mason, P. A. (1984). Upper echelons: The organization as a reflection of its top managers. Academy of Management Review, 9, 193-206.

Hrebiniak, L., \& Joyce, W. (1985). Organizational adaptation: Strategic choice and environmental determinism. Administrative Science Quarterly, 35, 336-349.

Hult, G. T. (2003). An integration of thoughts on knowledge management. Decision Sciences, 34(2), 189-195.

Kabanoff, B., \& Brown, S. (2008). Knowledge structures of prospectors, analyzers, and defenders: Content, structure, stability, and performance. Strategic Management Journal, 29, 149-171.

Kae, R., Paauwe, J., \& Zupan, N. (2009). HR practices, interpersonal relations, and intrafirm knowledge transfer in knowledge-intensive firms: a social network perspective. Human Resource Management, 48(4), 615-639.

Landis, R. S., Bela, D. J., \& Tesluk, P. E. (2000). A comparison of approaches to composite measures in structural equation models. Organizational Research Methods, 3(2), 186-207.

Lepak, D. P., \& Snell, S. A. (1999). The human resource architecture: Toward a theory of human capital allocation and development. Academy of Management Review, 24(1), 31-48.

Lopez-Cabrales, A., Pérez-Luño, A., \& Valle-Cabrera, R. (2009). Knowledge as a mediator between HRM practices and innovative activity. Human Resource Management, 48(4), 485-503.

March, J. S., \& Simon, H. A. (1958). Organizations. New York: Wiley.

Mezias, J., \& Starbuck, W. (2003). Studying the accuracy of managers' perceptions: A research odyssey. British Journal of Management, 14, 3-17.

Miles, R. E., \& Snow, C. C. (1978). Organization strategy, structure and process. New York: McGrawHill.

Minbaeva, D. B. (2005). HRM practices and MNC knowledge transfer. Personnel Review, 34(1), $125-144$.

Minbaeva, D., Foss, N., \& Snell, S. (2009). Bringing the knowledge perspective into HRM. Human Resource Management, 48(4), 477-483.

Mohrman, S. A., \& Worley, C. W. (2009). Dealing with rough times: a capabilities development approach to surviving and thriving. Human Resource Management, 48(3), 433-445.

Nahm, A. Y., Vonderembse, M. A., \& Koufteros, X. A. (2004). The impact of organizational culture on time-based manufacturing and performance. Decision Sciences, 35(4), 579-607. 
Ngo, H. Y., Lau, C. M., \& Foley, S. (2008). Strategic human resource management, firm performance, and employee relations climate in China. Human Resource Management, 47(1), 73-90.

Nilsen, D., \& Campbell, D. P. (1993). Self-observer rating discrepancies: Once an overrater, always an overrater? Human Resource Management, 32(2/3), 265-281.

O'Regan, N., \& Ghobadian, A. (2005). Innovation in SMEs: The impact of strategic orientation and environmental perceptions. International Journal of Productivity and Performance Management, 54(9), 81-97.

Olson, E. M., Slater, S. F., \& Hult, G. T. M. (2005). The performance implications of fit among business strategy, marketing orientation structure, and strategic behavior. Journal of Marketing, 69(3), 49-65.

Pedler, M., Burgoyne, J., \& Boydell, T. (1991). The learning company: A strategy for sustainable development. London: McGraw-Hill.

Pfeffer, J., \& Salancik, G. (1978). The external control of organizations. New York: Harper \& Row.

Porter, M. E. (2001). Strategy and the internet. Harvard Business Review, 79(2), 63-78.

Powell, T. C., Lovallo, D., \& Caringal, C. (2006). Causal ambiguity, management perception, and firm performance. Academy of Management Review, 31(1), 175-196.

Prahalad, C. K., \& Hamel, G. (1990). The core competence and the corporation. Harvard Business Review, 68, 79-91.

Rajagopalan, N. (1996). Strategic orientations, incentive plan adoptions and firm performance: Evidence from electric utility firms. Strategic Management Journal, 18, 761-785.

Robbins, S. P. (1998). Organizational behavior: Concepts, controversies, applications (8 ed.). London: Prentice Hall.

Robinson, R. B., \& Pearce, J. A. (1988). Planned patterns of strategic behavior and their relationship to business-unit performance. Strategic Management Journal, 9, 43-60.

Rollinson, D., Broadfield, A., \& Edwards, D. (1998). Organisational Behaviour and Analysis. Harlow: Addison-Wesley.

Shook, C. L., Ketchen, D. J., Hult, G. T. M., \& Kacmar, K. M. (2004). An assessment of the use of structural equation modeling in strategic management research. Strategic Management Journal, 25, 397-404.

Short, J. C., Payne, G. T., \& Ketchen, D. J. (2008). Research on organizational configurations: Past accomplishments and future challenges. Journal of Management, 34, 1053-1079.

Shortell, S. M., \& Zajac, E. J. (1990). Perceptual and archival measures of Miles and Snow's strategic types: A comprehensive assessment of reliability and validity. Academy of Management Journal, 33(4), 817-832.

Slater, S. F., Olson, E. M., \& Hult, G. T. M. (2006). The moderating influence of strategic orientation on the strategy formation capability-performance relationship. Strategic Management Journal, 27(3), 1221-1231.

Smith, K. G., Guthrie, J. P., \& Chen, M. (1989). Strategy, size and performance. Organizational Studies, $10(1), 63-81$.

Snow, C. C., \& Hrebiniak, L. G. (1980). Measuring organizational strategies. Some theoretical and methodological problems. Academy of Management Review, 5(4), 527-538.

Song, M., Calantone, R. J., \& Di Benedetto, C. A. (2002). Competitive forces and strategic choice decisions: An experimental investigation in the United States and Japan. Strategic Management Journal, 23, 969-978.

Starbuck, W., \& Mezias, J. (1996). Opening pandora's box: Studying the accuracy or managers' perceptions. Journal of Organization Behavior, 17, 99-117.

Subramony, M. (2009). A meta-analytic investigation of the relationship between HRM bundles and firm performance. Human Resource Management, 48(5), 745-768.

Teece, D. J. (2007). Explicating dynamic capabilities: The nature and microfoundations of (sustainable) enterprise performance. Strategic Management Journal, 28, 1319-1350.

Tornow, W. W. (1993). Perceptions or reality? Is multi-perspective measurement a means or an end? Human Resource Management, 32, 2211-2229.

Tracey, M. A., Vonderembse, M. A., \& Lim, J. S. (1999). Manufacturing technology and strategy formulation: Keys to enhancing competitiveness and improving performance. Journal of Operations Management, 17(4), 411-428.

Van Velsor, E., Taylor, S., \& Leslie, J. B. (1993). An examination of the relationships among selfperception accuracy, self-awareness, gender, and leader effectiveness. Human Resource Management, 32(2/3), 249-263.

Wahab, S., \& Cooper, C. (2001). Tourism in the age of globalisation. London: Routledge. 
Wang, H. C., He, J., \& Mahoney, J. T. (2009). Firm-specific knowledge resources and competitive advantage: The roles of economic-and relationship-based employee governance mechanisms. Strategic Management Journal, 30, 1265-1285.

Wernerfelt, B. (1984). A resource-based view of the firm. Strategic Management Journal, 5, 171-180.

Winter, S. G. (2003). Mistaken perceptions: Cases and consequences. British Journal of Management, 14, $39-44$.

Wright, M. (2001). Entrepreneurship and wealth creation. Sue Birley reflects on creating and growing wealth. European Management Journal, 19(2), 128-139.

Wyer, P., Mason, J., \& Theodorakopoulos, N. (2000). Small business development and the 'learning organisation'. International Journal of Entrepreneurial Behavior \& Research, 6(4), 239-259.

Yamao, S., De Cieri, H., \& Hutchings, K. (2009). Transferring subsidiary knowledge to global headquarters: Subsidiary senior executives' perceptions of the role of HR configurations in the development of knowledge stocks. Human Resource Management, 48(4), 531-554.

Yammarino, F. J., \& Atwater, L. E. (1993). Understanding self-perception accuracy: Implications for human resource management. Human Resource Management, 32(2-3), 231-247.

Yang, J. T., \& Wan, C. S. (2004). Advancing organizational effectiveness and knowledge management implementation. Tourism Management, 25, 593-601.

Zahra, S. A., \& Pearce, J. A. (1990). Research evidence on the Miles and Snow typology. Journal of Management, 16(4), 751-768.

Zajac, E., \& Shortell, S. (1989). Changing generic strategies: likelihood, direction and performance implications. Strategic Management Journal, 10(5), 413-430. 